\title{
Chemical composition and anxiolytic-like effects of the Bauhinia platypetala
}

\section{Francisco José Borges dos Santos, ${ }^{1,2}$ Sidney Gonçalo de Lima, ${ }^{3}$ Gilberto S. Cerqueira, ${ }^{3}$ Antônia Maria das Graças Lopes Citó, ${ }^{3,4}$ Ana Amélia de Carvalho Melo Cavalcante, ${ }^{3,5}$ Thiago Henrique Costa Marques, ${ }^{6}$ Rivelilson Mendes de Freitas ${ }^{* 3,6}$}

${ }^{1}$ Laboratório de Toxicologia Genética, Programa de Pós-graduação em Genética e Toxicologia Aplicada, Universidade Luterana do Brasil, Brazil,

${ }^{2}$ Departamento de Química, Instituto Federal do Piauí, Brazil,

${ }^{3}$ Programa de Pós-graduação em Ciências Farmacêuticas, Universidade Federal do Piauí, Brazil,

${ }^{4}$ Departamento de Química, Universidade Federal do Piauí, Brazil,

${ }^{5}$ Faculdade Novafapi, Piaui, Brazil.

${ }^{6}$ Departamento de Bioquímica e Farmacologia, Programa Pós-graduação Farmacologia, Universidade Federal do Piauí, Brazil.
Revista Brasileira de Farmacognosia Brazilian Journal of Pharmacognosy 22(3): 507-516, May/Jun. 2012

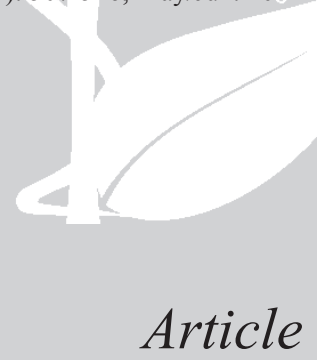

Received 26 Aug 2011

Accepted 3 Oct 2011

Available online 24 Jan 2012

\begin{abstract}
The pantropical genus Bauhinia, Fabaceae, known popularly as cow's foot, is widely used in folk medicine as antidiabetic. Behavioral effects of the ethanolic extract and ethereal, aqueous and ethyl acetate fractions from B. platypetala Benth. ex Hemsl. leaves were studied in male Swiss mice. The ethanolic extract and fractions were administered intraperitoneally and its effects on spontaneous motor activity (total motility, locomotion, rearing and grooming behavior) were monitored. Anxiolytic-like properties were studied in the elevated plus-maze test and the possible antidepressantlike actions were evaluated in the forced swimming test. The results revealed that only the highest dose of the ethereal fraction $(50 \mathrm{mg} / \mathrm{kg}$, i.p. $)$ caused a significant decrease in total motility, locomotion and rearing. Sole dose injected $(50 \mathrm{mg} / \mathrm{kg})$ of ethanolic extract and ethereal fractions increased the exploration of the elevated plus-maze open arms in a similar way to that of diazepam $(2 \mathrm{mg} / \mathrm{kg}$, i.p. $)$. In the forced swimming test, the ethanolic extract and their fractions $(12.5,25$ or $50 \mathrm{mg} / \mathrm{kg}$ ) was not as effective as paroxetine (10 or $20 \mathrm{mg} / \mathrm{kg}$, i.p.) and imipramine (25 or $50 \mathrm{mg} / \mathrm{kg}$, i.p.) in reducing immobility. These results suggest that some of the components of the ethanolic extract and of the ethereal fraction from $B$. platypetala, such as p-cymene, phytol, D-lactic acid, hexadecanoic acid, among others, may have anxiolytic-like properties, which deserve further investigation. Furthermore, the results obtained indicate that ethanolic extract from B. platypetala and their fractions do not present antidepressive properties. However, these properties cannot be related to the chemical constituents identified in this specie.
\end{abstract}

ISSN 0102-695X http://dx.doi.org/10.1590/S0102$695 \times 2012005000018$

\section{Introduction}

Extracts from a wide variety of plant species have become popular in recent years, and attempts are being made to research their biological properties for human welfare (Ferreira et al., 2007; Samarth et al., 2008; Ferreira et al., 2009). Leaves of the pantropical genus Bauhinia, Fabaceae, are known popularly as cow's foot due to their unique characteristic bilobed aspect. The leaves of the neotropical species Bauhinia forficata (Brazilian orchid-tree) are widely used in folk medicine as antidiabetic (Yeh et al., 2003). This pharmacologic effect was demonstrated since studies with aqueous and alcoholic $B$. forficata extracts showed antidiabetic effect
(Fuentes et al., 2004; Volpato et al., 2004; Volpato et al., 2008), and antioxidant activity, which is a beneficial feature in diabetes complications prevention associated with oxidative stress (Khalil et al., 2008).

Data from the World Health reports (WHO, 2001) have demonstrated that approximately 450 million people suffer from a mental or behavioral disorder. The prevalence of anxiety mental condition has risen in recent years (Andrews et al., 2000) and depressive disorders are common and often disabling (Pan et al., 2005). Therefore, anxiety disorders are considered the most common psychiatric diagnoses, affecting between 10-30\% of the general population (Greenberg et al., 1999; Wittchen \& Hoyer 2001). Excess anxiety can be debilitating and 
damage the quality of life. Benzodiazepines have been extensively used for the treatment of several forms of anxiety, although these compounds have well known side effects such as sedation, muscle relaxation, amnesia and dependence (Jordan et al., 1996; Rickels \& Schweizer, 1997).

It is well known the use of raw materials from the Northeast of Brazil to the development of new anxiolytic drugs. This is a strategic field and at the same time a challenge. The surveys require large investments and the results usually take several years to appear. In this context, an ethanolic extract from Bauhinia platypetala Benth. ex Hemsl. leaves was obtained, their ethereal, aqueous and ethyl acetate fractions were prepared to evaluate their properties in the central nervous system (CNS) of mice. Recently, various other types of herbal medicines have been analyzed for their anxiolytic capacity (Rex et al., 2002), reinforcing the interest of the evaluation of possible properties on CNS of the species under study.

B. platypetala is widely used by Brazilian folk medicine to treat diabetes. However, research in literature has shown that there are no studies to ensure its use on neurodegenerative diseases and in development of CNS. Moreover, the possible toxic effects of extracts or natural fractions derived from these plant were yet not determined.

None of the extracts and their fractions has been submitted to the neuropharmacological evaluation. Since the whole ethanolic extract and fractions from $B$. platypetala has shown in previous studies in our laboratory sedative effects, it could be active on neuronal pathways related with psychiatric disorders, such as anxiety and depression. However, despite intensive research efforts of various research groups, the pharmacological actions accounting for the proved efficacy of $B$. platypetala on CNS disorders remain unclear. Experimental paradigms such as open field, elevated plus-maze, and forced swimming tests are widely used to identify putative candidates for new treatments obtained from natural sources for anxiety and depression.

The present study investigated whether the administration of ethanolic extract and ethereal, aqueous and ethyl acetate fractions of the leaves from $B$. platypletala produces behavioral modifications in mice. We evaluated spontaneous motor responses and the anxiolytic and antidepressive-like effects were assessed in the elevated plus-maze test and in the forced swimming test, respectively.

\section{Material and Methods}

\section{Chemicals}

All of the solvents were bidistilled and stored in dark flasks. Tween 80 and reserpine sulphate were purchased from Sigma (St. Louis, MO, USA). Diazepam (DZP) was purchased from the União Química (Fortaleza, CE, Brazil) and used as standard. Imipramine (IMI) and Paroxetine (PAROX) were purchased from the Novartis Biociências S.A. (São Paulo, SP, Brazil) and Glaxo Smith Kline Brasil Ltda (Rio de Janeiro, RJ, Brazil), respectively. All other drugs were of analytical grade.

\section{Plant material}

Bauhinia platypetala Benth. ex Hemsl., Fabaceae/Cercideae, also known as cow's foot or "capabode" was collected in areas of Federal University of Federal do Piauí in Teresina, Piauí, Brazil, and stored at room temperature in a dark and dry place prior to use. The plant was collected by Francisco José Borges dos Santos and identified by Dra. Ângela Maria Studart da Fonseca Vaz in March 2010, at the Botanic Garden Research Institute of Rio de Janeiro, state of Rio de Janeiro, Brasil. A sample was deposited at the Graziela Barroso, Herbarium of the Federal University of Piaui (voucher specimen $\left.n^{\circ} 24.875\right)$. Ethanolic extract (EE), ethereal (EF), aqueous (AF) and ethyl acetate (EAF) fractions from B. platypetala leaves were prepared at Laboratory of Chemistry from Department of Chemistry of the Federal Institute of Piauí (Protocol number \#044/2009).

Preparations of ethanolic extract, ethereal, aqueous and ethyl acetate fractions from $\mathrm{B}$. platypetala

The leaves were collected and dried at room temperature and ground into powder. Dry powder (1300 g) was macerated exhaustively in $95 \%$ ethanol $(\mathrm{w} / \mathrm{w})$, sixteen days. The resulting ethanolic extract $(5.9 \%)$ was filtered and concentrated under reduced pressure. The concentrated part (800 g) was partitioned into diethyl ether and ethyl acetate, respectively. Resulting in the aqueous (13.79\%), ethereal (17.24\%) and ethyl acetate $(3.45 \%)$ fractions. The ethanolic extract and fractions (ethereal, aqueous and ethyl acetate) were lyophilized. The extract and fractions dried was kept at $4{ }^{\circ} \mathrm{C}$ in the air tight bottles until use.

Phytochemical screening and gas chromatography-mass spectrometry (GC-MS)

To determine the chemical constituents, qualitative phytochemical screening of the B. platypetala ethanolic extract was carried out following standard procedures routinely used in the laboratory (Barbosa, 2004; Matos, 2009). Pretreatment of the fractions in BSTFA ( $N, O$-bis(trimethylsilyl) trifluoroacetamide) and TMCS (trimethylchlorosilane) was perfomed as described (Hegazi \& Abd El Hady, 2002).

Analysis of the fractions was performed on 
Shimadzu GC-17A/MS QP5050A (GC-MS system): DB-5HT capillary column $(30 \mathrm{~m} \times 0.251 \mathrm{~mm}, 0.1 \mu \mathrm{m}$ film thickness); carrier gas: helium $1.7 \mathrm{~mL} / \mathrm{min}$; column inlet pressure $107.8 \mathrm{kPa}$; column flow $1.7 \mathrm{~mL} / \mathrm{min}$; linear velocity $47.3 \mathrm{~cm} / \mathrm{s}$; total flow $24 \mathrm{~mL} / \mathrm{min}$; carrier flow $24 \mathrm{~mL} / \mathrm{min}$; injector temperature $280{ }^{\circ} \mathrm{C}$; detector temperature $300{ }^{\circ} \mathrm{C}$; column temperature $100(1 \mathrm{~min})$ - $310{ }^{\circ} \mathrm{C}$ at $10{ }^{\circ} \mathrm{C} / \mathrm{min}(15 \mathrm{~min})$. Mass spectrometer operating conditions were $70 \mathrm{eV}$ of ionization energy. Mass spectra were recorded from $40-450 \mathrm{~m} / \mathrm{z}$. The percent of area was obtained electronically from the GCMS response without the use of an internal standard or correction factors.

\section{Animals and behavioral tests}

Male Swiss adult mice (25-30 g) were used. All animals were maintained at a controlled temperature $\left(25 \pm 2{ }^{\circ} \mathrm{C}\right)$ and a 12 -h dark/light cycle. Animals had free access to water and food. All behavioral tests were conducted in quiet rooms at the same controlled conditions referred above and isolated from external noise. Different groups of mice were used for each behavioral task. For each experiment, mice were randomized into five groups (seven mice per group): one control group treated with the vehicle, four groups treated with EE or ethereal (EF), aqueous (AF) or ethyl acetate (EAF) fractions at $50 \mathrm{mg} /$ $\mathrm{kg}$, and a six drug reference group treated with imipramine 25 or $50 \mathrm{mg} / \mathrm{kg}$, paroxetine 10 or $20 \mathrm{mg} / \mathrm{kg}$ and reserpine $0.25 \mathrm{mg} / \mathrm{kg}$ (forced swimming) or DZP $0.75 \mathrm{mg} / \mathrm{kg}$ (open field and elevated plus maze test). Treatment with EE, EF, $\mathrm{AF}, \mathrm{EAF}$ or vehicle was given intraperitoneal route (i.p.) via gastric gavage $(1 \mathrm{~mL} / \mathrm{kg})$ for $24 \mathrm{~h}$. The imipramine intraperitoneal (i.p.) administration and oral treatment with DZP were done 30 and $60 \mathrm{~min}$ before the tests, respectively, following the schemes of the other authors (Tadano et al., 2000; Griebel et al., 2001; Kulkarni \& Dhir, 2007). All experiments were performed according to the Guide for the Care and Use of Laboratory Animals, from the US Department of Health and Human Services, Washington DC, 1985. The protocols for the animals experiments described in this study were performed in accordance with international (EEC Directive of 1986, 86/609/EEC) and national rules and institutional guidelines as prescribed by the ethical committee for animal experiments of the Federal University of Piaui (CEEA/UFPI \# 44/09).

\section{Experimental protocol and behavioral screening}

After the treatment, each animal was submitted to a series of tests in the manner described below. Firstly, the animal was observed in a closed room, at constant temperature $\left(25 \pm 2^{\circ} \mathrm{C}\right)$. The animal was then placed inside a plus maze and observed for $5 \mathrm{~min}$. Immediately, after the plus maze test, it was placed in the open field area for $5 \mathrm{~min}$ and its temperature was taken with a digital thermometer. All the tests were performed between 8 am and $18 \mathrm{pm}$. Behavioral screening of the mice was performed following parameters described by Almeida and collaborators (1999) and animals were observed for $24 \mathrm{~h}$ i.p. administration of EE, EF, AF, EAF from $B$. platypetala $(12.5,25$ or $50 \mathrm{mg} / \mathrm{kg}$, i.p.). During $24 \mathrm{~h}$ were observed the occurrence of the following general signs of toxicity: piloerection, prostration, writhing, increased evacuation, grooming, discrete groups, dyspnea, sedation, analgesia and palpebral ptosis.

\section{Open field test}

The open field area was made of acrylic (transparent walls and black floor, $30 \times 30 \times 15 \mathrm{~cm}$,) divided into nine squares of equal area. The open field was used to evaluate the exploratory activity of the animal (Archer, 1973). The observed parameters were: number of squares crossed (with the four paws) and numbers of grooming and rearing.

\section{Elevated-plus-maze test (EPM)}

The elevated-plus-maze for mice (Lister, 1987) consisted of two perpendicular open arms $(30 \times 5 \mathrm{~cm})$ and two closed arms $(30 \times 5 \times 25 \mathrm{~cm})$ also in perpendicular position. The open and closed arms were connected by a central platform $(5 \times 5 \mathrm{~cm})$. The platform and the lateral walls of the closed arms were made of transparent acrylic. The floor was made of black acrylic. The maze was $45 \mathrm{~cm}$ above the floor. After treatment, the animal was placed at the center of the plus maze with its nose in the direction of one of the closed arms, and observed for $5 \mathrm{~min}$, according to the following parameters: number of entries in the open and closed arms, and time of permanence in each of them. The time of permanence measures the time spent by the animal in the open and closed arms. Anxiolytic compounds reduce the natural animal's aversion to the open arms and promotes the exploration thereof. On the other hand, the forced or voluntary passages of the animal into the open arms of the EPM are associated with hormonal and behavioral changes indicative of increased anxiety (Hogg, 1996). These tests were done in different places, justifying the use of this apparatus.

\section{Forced swimming test}

This test is the most widely used and recognized pharmacological model (Porsolt et al., 1978), for assessing antidepressant activities (Porsolt et al., 1977a). In the present work, we employed that described by Porsolt and collaborators (Porsolt et al., 1977b). The development of immobility when mice were placed inside an inescapable 
cylinder filled with water.

In order to clarify the antidepressant effect of the EE, EF, AF and $\mathrm{EAF}(12.5,25$ or $50 \mathrm{mg} / \mathrm{kg}$ i.p.), imipramine $(25$ or $50 \mathrm{mg} / \mathrm{kg}$ ) and paroxetine $(10$ or 20 $\mathrm{mg} / \mathrm{kg}$ ) alone were used in the forced swimming test. Imipramine was chosen because this drug is a classical antidepressant that acts through noradrenergic and serotonergic pathways. Paroxetine, another antidepressant drug, is more selective, and acts predominantly through serotonergic pathways. Both antidepressants were then used, alone as positive controls. In addition, reserpine, a drug known to cause depletion of biogenic amines (noradrenaline, dopamine and serotonin) from storage granules, was also used to evaluate the participation of those amines in the antidepressant effect.

If the initial assessment of the effects of ethanol extract and fractions of $B$. platypetala at doses of 12.5 , 25 or $50 \mathrm{mg} / \mathrm{kg}$ (i.p.) demonstrated satisfactory results as an antidepressant agent, we intend to test the extract and its fractions in combination with antidepressant agents (positive controls) to investigate alteration/interference of imipramine or paroxetine on the antidepressant effect only of $B$. platypetala. In a combination protocol, imipramine, paroxetine or reserpine were administered $10 \mathrm{~min}$ before ethanolic extract and fractions, and the test was performed $30 \mathrm{~min}$ later.

\section{Rectal temperature}

Screening for animals' rectal temperature effects of the ethanolic extract and their fractions were evaluated in mice according to the method described by Williamson and collaborators (1982). A thermistor probe was inserted about $3 \mathrm{~cm}$ into the rectum of each mouse and their basal rectal temperatures were recorded on a digital thermometer.

\section{Statistical analysis}

All results obtained from the different tests were compared against the control group by using Analysis of Variance (ANOVA) and followed by $t$-Student-Neuman-Keuls as a post hoc test. Differences between experimental groups were considered statistically significant when $\mathrm{p}$ was less than 0.05 .

\section{Results}

Chemical analysis of the ethanolic extracts of the leaves from B. platypetala

Phytochemical screening of the ethanolic extracts indicated the presence of flavonoids, cumarin, triterpenoids/steriods and tannins and the absence of alkaloids and saponins. A GC-MS analysis indicated the presence of various constituents in the B. platypetala in the aqueous, ethyl acetate and ethereal fractions (Table $1)$.

Table 1. Main components of the fractions of the ethanolic extract from Bauhinia platypetala.

\begin{tabular}{llc}
\hline \multicolumn{1}{c}{ Fraction } & \multicolumn{1}{c}{ Component } & (\%) \\
\hline Ethereal fraction & p-cymene & 7.3 \\
& phytol & 9.8 \\
& D-lactic acid & 26.41 \\
& hexadecanoic acid & 26.41 \\
Ethyl acetate fraction & octadecanoic acid & 36.04 \\
& hexadecanoic acid & 20.87 \\
& myo-inositol & 6.44 \\
Aqueous fraction & neo-inositol & 4.34 \\
& myo-inositol & 60.90 \\
& hexadecanoic acid & 3.50 \\
& esculin & 4.60 \\
\hline
\end{tabular}

GC-MS: gas chromatography-mass spectrometry (GC-MS) and identification of components.

Behavioral screening of groups of mice which received ethanolic extract and fractions from $\mathrm{B}$. platypetala

The B. platypetala ethanolic extract, ethereal fraction, aqueous fraction or ethyl acetate fraction neither altered motor activity and respiratory rate and did not induce tremors and clonic convulsions at $12.5,25$ or 50 $\mathrm{mg} / \mathrm{kg}$ (i.p.), showing no signs of toxicity.

Open-field test of groups of mice which received vehicle, ethanolic extract and fractions from B. platypetala

In the open field test, DZP decreased significantly $(p<0.001)$ the number of square crossed, rearings and groomings. On the other hand, B. platypetala ethanolic extract, aqueous and ethyl acetate fractions did not induce changes in these same parameters. However, ethereal fraction at dose $50 \mathrm{mg} /$ $\mathrm{kg}$ induced a reduction only the in number of square crossed and rearings ( $p<0.05$; Figure 1).

Spontaneous locomotor activity of each animal was measured in open field test. The animals were submitted to a first trial in the chambers $1 \mathrm{~h}$ after vehicle, DZP, ethanolic extract and fractions from B. platypetala treatments. Twenty-four hours later, the animals were tested in the same activity chamber used in the previous day without drug treatment for $5 \mathrm{~min}$, and the number of squares crossed, rearing and grooming was recorded again. In acute experiments, the $B$. platypetala extract and fractions were administered $30 \mathrm{~min}$ before the second trial. The locomotor activity in the first trial was used as 
an index of sedative/excitatory effect, whereas the activity in the second trial was used as index of habituation, a model of non-associative memory. Mice treated with DZP or ethereal fraction at dose $50 \mathrm{mg} / \mathrm{kg}$ (i.p.) showed a decrease in the locomotor activity (number of squares crossed) between the first and the second trial, which indicated habituation (Platel \& Porsolt, 1982).
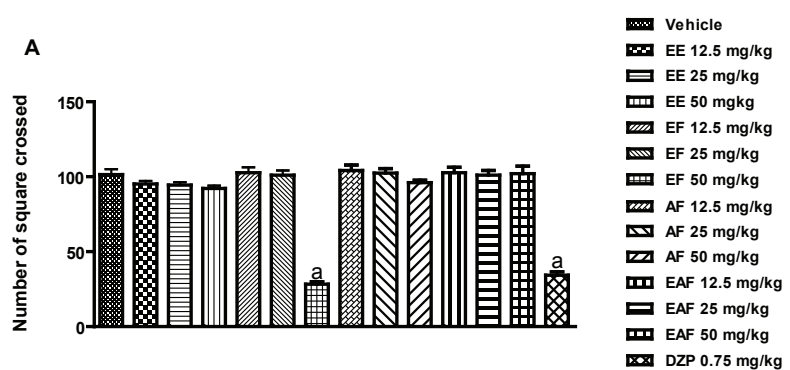

B

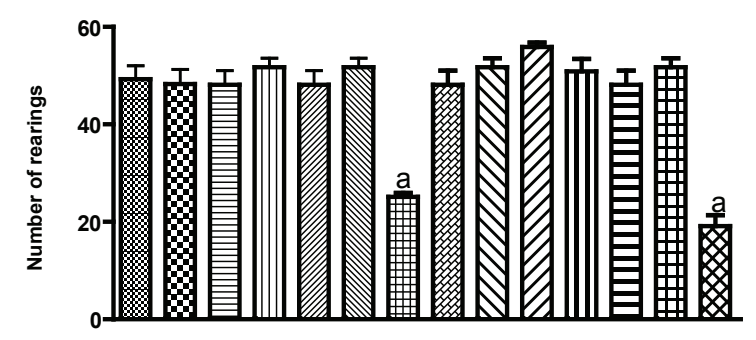

C

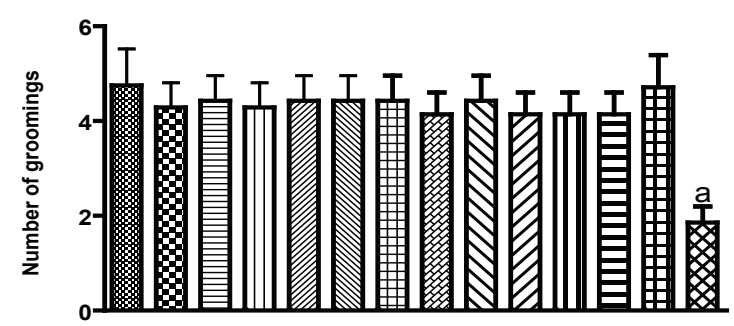

Figure 1. Open-field test of groups of mice which received vehicle, ethanolic extract and fractions $(12.5,25$ or $50 \mathrm{mg} / \mathrm{kg}$, i.p.) from B. platypetala and DZP $(0.75 \mathrm{mg} / \mathrm{kg}$ i.p. $)$. (A) Number of squares crossed; (B) Rearing; (C) Grooming: $n=7$ animals per group; Vehicle = Negative control; DZP = diazepam; Ethanolic extract $=\mathrm{EE}$; Ethereal fraction $=\mathrm{EF}$; Aqueous fraction $=$ AF: Ethyl Acetate fraction $=\mathrm{EAF}$. The results are presented as mean \pm SEM. Significant difference compared with vehicle ${ }^{\mathrm{a}} p<0.001$ (ANOVA and $t$-Student-Newman-Keuls as the post hoc test).

Effects of ethanolic extract and fractions from B. platypetala in the elevated-plus-maze test
In this model, DZP significantly increased $(p<0.001)$ the number of entries and the time spent in the open arms. On the other hand, ethereal fraction did not induce any reductions only in percentage of entries in the open arms ( $p>0.05$; Table 2$)$.

Animals which received $50 \mathrm{mg} / \mathrm{kg}$ (i.p.) of ethanolic extract from $B$. platypetala presented a significant decrease of percentage of entries in open arms $(p<0.05)$, and increased the time and percentage on the open arms $(p<0.005)$ of the plus maze as well as reduced the number of entries $(p<0.05)$ in open arms $(p<0.001)$ (Table 2). Aqueous fraction from B. platypetala $50 \mathrm{mg} / \mathrm{kg}$ caused increment of percentage of entries in open arms $(p<0.05)$, and number of entries $(p<0.05)$ in open arms $(p<0.001)$. On the other hand, ethyl acetate fraction at dose $12.5,25$ or $50 \mathrm{mg} / \mathrm{kg}$ (i.p.) did not induce changes in these same parameters $(p<0.05$; Table 2$)$.

Effects of ethanolic extract and fractions from $\mathrm{B}$. platypetala in the forced swimming test

The effects of $B$. platypetala on the immobility time in the forced swimming test are presented in Table 3. ANOVA showed a significant difference in the effects of imipramine when compared with vehicle in IMI 25 $(p<0.001)$ and IMI 50 groups $(p<0.01)$ (Table 3$)$. No significant difference between ethanolic extract, aqueous fraction, ethereal fraction, ethyl acetate fraction groups and vehicle-treated mice was observed $(p>0.05)$.

All animals treated with the ethanolic extract, aqueous, ethereal, ethyl acetate fractions from $B$. platypetala no showed antidepressant behavior $(p>0.05)$, while animals administered with the standard antidepressant drugs, IMI and PAR, showed a significantly $(p<0.05)$ decreased time of immobility. Similarly, the animals co-administered with ethanolic extract and fractions from $B$. platypetala plus IMI or PAR did not show changes on time of immobility (Table $3, p>0.05$ ). In contrast, animals administered with the RESERP, showed a significant $(p<0.05)$ increase in time of immobility. Similarly, the animals co-administered with ethanolic extract and fractions from $B$. platypetala plus RESERP, also no presented a significant $(p>0.05)$ alterations in time of immobility (Table 3 ).

Retal temperature of mice after administration of ethanolic extract and fractions from B. platypetala

Table 4 shows antipyretic properties of $B$. platypetala, in particular with the ethereal fraction at dose $50 \mathrm{mg} / \mathrm{kg}$ (i.p.). Unlikely, B. platypetala did not show a decrease in antipyretic activity with time with ethanolic extract, aqueous fraction and ethyl acetate fraction. Only $50 \mathrm{mg} / \mathrm{kg}$ (i.p.) administration of ethereal fraction from $B$. platypetala is effective than that of the ethanolic extract 
Table 2. Effect produced by dose $(12.5,25$ or $50 \mathrm{mg} / \mathrm{kg}$, i.p. $)$ of ethanolic extract and fractions from B. platypetala upon number of entries by mice in open arms on the elevated-plus-maze test.

\begin{tabular}{lcccc}
\hline Groups $(\mathrm{mg} / \mathrm{kg})$ & NEOA & PEOA & TPOA & PTOA \\
\hline Vehicle & $10.86 \pm 0.94$ & $40.19 \pm 3.45$ & $141.0 \pm 4.04$ & $46.96 \pm 1.43$ \\
DZP 0.75 & $15.71 \pm 0.29^{\mathrm{a}}$ & $58.24 \pm 1.06^{\mathrm{a}}$ & $206.90 \pm 2.7^{0 \mathrm{a}}$ & $68.00 \pm 8.84^{\mathrm{a}}$ \\
EE 12.5 & $10.12 \pm 0.73$ & $57.94 \pm 3.36$ & $142.60 \pm 3.45$ & $45.87 \pm 1.93$ \\
EE 25 & $10.57 \pm 0.73$ & $56.74 \pm 4.26$ & $143.50 \pm 2.91$ & $47.01 \pm 1.37$ \\
EE 50 & $10.40 \pm 0.93$ & $40.70 \pm 5.37$ & $145.20 \pm 3.78$ & $45.12 \pm 4.72$ \\
EF 12.5 & $10.25 \pm 0.53$ & $57.40 \pm 6.07$ & $142.30 \pm 5.64$ & $46.67 \pm 8.55$ \\
EF 25 & $9.36 \pm 0.34$ & $56.95 \pm 4.31$ & $148.20 \pm 3.64$ & $47.06 \pm 5.43$ \\
EF 50 & $17.96 \pm 0.75^{\mathrm{a}}$ & $52.28 \pm 3.25$ & $273.60 \pm 3.39^{\mathrm{a}}$ & $74.60 \pm 1.21^{\mathrm{a}}$ \\
AF 12.5 & $10.60 \pm 1.95$ & $56.15 \pm 7.80$ & $141.52 \pm 7.89$ & $45.97 \pm 5.96$ \\
AF 25 & $10.40 \pm 1.34$ & $57.60 \pm 5.37$ & $143.60 \pm 3.85$ & $47.87 \pm 1.39$ \\
AF 50 & $10.89 \pm 0.77$ & $74.10 \pm 7.58^{\mathrm{a}}$ & $136.0 \pm 4.16$ & $45.20 \pm 2.48$ \\
EAF 12.5 & $11.12 \pm 0.97$ & $39.95 \pm 3.37$ & $139.50 \pm 4.65$ & $47.24 \pm 2.85$ \\
EAF 25 $50.54 \pm 0.57$ & $40.40 \pm 5.22$ & $139.95 \pm 3.12$ & $45.96 \pm 3.43$ \\
EAF 50 & $10.54 \pm 0.96 \pm 0.29$ & $41.79 \pm 2.96$ & $141.0 \pm 4.04$ & $46.96 \pm 14.3$ \\
\hline
\end{tabular}

$\mathrm{n}=7$ animals per group; Data were presented as mean \pm SEM. Vehicle: negative control; DZP: diazepam (0.75 mg $/ \mathrm{kg}$, i.p.); Ethanolic extract: EE; Ethereal fraction: EF; Aqueous fraction: AF; Ethyl acetate fraction: EAF. ${ }^{a} p<0.001$ (ANOVA and t-Student-Newman-Keuls as the post hoc test).

and fractions tested for the first $2 \mathrm{~h}$ after administration. There were not, however, potency differences between the lower doses 12.5 and $25 \mathrm{mg} / \mathrm{kg}$ of ethereal fraction administration. The effect of yeast appeared to reduce after $4 \mathrm{~h}$ of ethereal fraction administration, as the temperature came back to normal after $5 \mathrm{~h}$ of distilled water administration (Table 4).

Ethanolic extract, DZP, aqueous and ethyl acetate fractions did not present reasonable antipyretic action (Table 4). The pharmacokinetic profile of dose (50 $\mathrm{mg} / \mathrm{kg}$ ) of ethereal fraction was observed to be somehow similar to that of acetylsalicylic acid (data not show). None of the animals manifested toxic effects at any of the dose levels of all extracts employed in the present study. Furthermore, all the animals survived the two weeks of observation.

\section{Discussion}

The genus Bahuinia belongs to the Fabaceae family and encompasses over 300 species widely distributed throughout the pantropical regions of the world, and in Brazil 250 native species have been identified. Members of the Bahuinia genus have commercial, economical, and medicinal importance. Economically, Fabaceae are employed worldwide in the production of pepper in spice markets. Plants from the genus Bahuinia have been used for a number of practical applications, like remedies in many traditional medicinal systems, such as traditional Chinese medicine, Indian and Vietnam as well as in Brazilian folklore. Depending on the species, Bauhinia flowers are usually in magenta, mauve, pink or white hues with crimson marking (United States Department of Agriculture, 2007).

Table 3. Effect of vehicle, ethereal fractions $(12.5,25$ or $50 \mathrm{mg} /$ $\mathrm{kg}$, i.p.) from Bauhinia platypetala in the immobility time for mice submitted to a forced swimming test.

\begin{tabular}{lc}
\hline \multicolumn{1}{c}{ Groups $(\mathrm{mg} / \mathrm{kg})$} & Immobility time $(\mathrm{s})$ \\
\hline Vehicle & $188.30 \pm 2.02$ \\
EE 12.5 & $184.20 \pm 3.65$ \\
EE 25 & $183.50 \pm 5.25$ \\
EE 50 & $186.00 \pm 5.91$ \\
EF 12.5 & $182.90 \pm 2.79$ \\
EF 25 & $187.30 \pm 3.91$ \\
EF 50 & $189.00 \pm 5.57$ \\
AF 12.5 & $189.50 \pm 3.17$ \\
AF 25 & $187.20 \pm 3.11$ \\
AF 50 & $185.90 \pm 3.89$ \\
EAF 12.5 & $185.50 \pm 3.45$ \\
EAF 25 & $186.80 \pm 1.21$ \\
EAF 50 & $182.90 \pm 4.78$ \\
IMI 25 & $115.00 \pm 0.57$ \\
IMI 50 & $75.00 \pm 0.68^{\mathrm{a}}$ \\
PAR 10 & $82.67 \pm 1.08^{\mathrm{a}}$ \\
PAR 20 & $133.00 \pm 3.28^{\mathrm{a}}$ \\
RESERP 0.25 & $263.70 \pm 2.15^{\mathrm{a}}$ \\
\hline
\end{tabular}

$\mathrm{n}=7$ animals per group; Data were presented as mean \pm SEM. Vehicle: negative control, imipramine: IMI; reserpine: RESERP; paroxitine: PAR; Ethanolic extract: EE; Ethereal fraction: EF; Aqueous fraction: AF; Ethyl acetate fraction: EAF. Significant difference compared with vehicle ${ }^{\mathrm{a}} p<0.001$ (ANOVA and t-Student-Newman-Keuls as the post hoc test). 
Table 4. Retal temperature of mice after administration of the vehicle, ethanolic extract and fractions $(12.5,25 \mathrm{or} 50 \mathrm{mg} / \mathrm{kg}$, i.p.) from Bauhinia platypetala and DZP $(0.75 \mathrm{mg} / \mathrm{kg})$.

\begin{tabular}{lc}
\hline Groups $(\mathrm{mg} / \mathrm{kg})$ & Rectal temperature $\left({ }^{\circ} \mathrm{C}\right)^{*}$ \\
\hline Vehicle & $38.00 \pm 0.82$ \\
DZP 0.75 & $38.01 \pm 1.00$ \\
EE 12.5 & $37.82 \pm 0.45$ \\
EE 25 & $37.92 \pm 0.85$ \\
EE 50 & $38.12 \pm 0.95$ \\
EF 12.5 & $37.85 \pm 0.42$ \\
EF 25 & $38.02 \pm 0.57$ \\
EF 50 & $33.80 \pm 1.30^{\mathrm{a}}$ \\
AF 12.5 & $38.02 \pm 0.85$ \\
AF 25 & $37.92 \pm 0.95$ \\
AF 50 & $37.90 \pm 1.82$ \\
EAF 12.5 & $38.05 \pm 0.85$ \\
EAF 25 & $38.10 \pm 0.42$ \\
EAF 50 & $38.10 \pm 0.42$
\end{tabular}

*Numbers are means \pm S.E.M. Vehicle: negative control; DZP: diazepam; Ethanolic extract: EE; Ethereal fraction: EF; Aqueous fraction: AF; Ethyl acetate fraction: EAF. $n=7$ animals per group; The results were presented as mean \pm S.E.M. Significant difference compared with vehicle ${ }^{\mathrm{a}} p<0.001$ (ANOVA and t-Student-Newman-Keuls as the post hoc test).

Extract and fractions from $B$. platypetala and vehicle (Tween $800.05 \%$ dissolved in $0.9 \%$ saline) were injected into the gastrointestinal tract with gavage. Two dose levels of the extracts, namely low (12.5 or $25 \mathrm{mg} /$ $\mathrm{kg}$ body weight) and high ( $50 \mathrm{mg} / \mathrm{kg}$ body weight), were selected from the pilot study carried out in mice based on the information obtained from traditional naturopaths.

Based on those considerations, we decided to investigate the ethanolic extract and fractions from $B$. platypetala effects on the CNS, since there are no studies about this substance in the literature on central actions. These observations also hint that the LD50 of the extracts is much higher than the highest dose level employed. Further research on the toxicity, including determination of LD50 of the ethanolic extract and fractions on this medicinal plant is underway.

The leaves of $B$. forficata Link are considered to be more effective for medicinal purposes than other species of Bauhinia. A chemical survey of the genus afforded mainly glycosil flavonoids (Yadava \& Tripathi, 2000), other phenolic derivatives (Reddy et al., 2003) and cyanoglycosides (Fort et al., 2001). The 6,7 -dihydroxycoumarin- $\beta$-D-glucopyranoside or esculin (coumarin), a main constituent present in the ethanolic extract, aqueous fraction of $B$. platypetala leaves (Table 1), is well known for its antioxidant activities (Kaneko et al., 2007). Coumarins comprise a group of phenolic compounds widely distributed in natural plants
(Neichi et al., 1983; Egan et al., 1990), and they have recently attracted much attention because of their broad pharmacological activities. Coumarins are somewhat lipophilic among natural antioxidants, but are more hydrophilic than a-tocopherol. $\alpha$-Tocopherol is located within cell membranes due to its chromane ring stabilized by hydrogen bonding with the ester carbonyl groups of phospholipids; coumarins are assumed to localize near the membrane surface similar to flavonoids (Ratty \& Das, 1988).

Hydroalcoholic and aqueous extracts from $B$. forficata present $O$-glycosyl flavonoid derivatives of kaempferol and quercetin (Pinheiro et al., 2006). Some attempts have been made to attribute the antidiabetic effects of the leaf extracts to the kaempferitrin, the major flavonoid derivative (Nijveldt et al., 2001).

Nevertheless, maternal glicemic control was not the mechanism by which $B$. forficata treatment reduced these anomalies rates. This fact could be related to the presence of substances present in this extract, which might act in glutathione antioxidant system and to promote an ameliorating activity of glutathione reduced $(\mathrm{GSH})$ through a compensatory mechanism in response to increased oxidative stress. Support for this hypothesis comes mainly from evidence that antioxidant enzymes provide protection against free radical induced malformations (Khalil et al., 2008). It has been reported that B. forficata and other plant extracts used in traditional medicines for human diabetes also have significant antioxidant activity, beneficial in the prevention of diabetes complications associated with oxidative stress (Masur et al., 1971).

In the present work, the effects of ethanolic extract and fractions from $B$. platypetala were studied in several behavioral animal models, such as elevatedplus-maze, open-field and forced swimming tests, in order to investigate its possible activity on CNS. These tests are classical models for screening CNS actions providing information about psychomotor performance, anxiety, locomotor activity and depression. It is well known that benzodiazepines act as anxiolytics (at low doses), anticonvulsants, and also produce sedation and a myorelaxant effect at higher doses. Thereby, our research group has used diazepam at $0.75 \mathrm{mg} / \mathrm{kg}$ in open field and in elevated plus maze tests and screening for antipyretic effects, as standard drug (Melo et al., 2006).

We have found that ethereal fraction reduces locomotor activity and has sedative and anxiolytic effects in mice. The general depressant activity of this fraction was confirmed by the decrease in the number or rearings and crossings in the open field test, since it is conceded that rearing is a function of the excitability level of the CNS (Masur et al., 1971). Ethereal fraction also showed anxiolytic-like effects when evaluated in the elevated plus maze. Anxiety, a symptom accompanying various 
CNS disorders and a disorder by itself, is characterized in humans by a tense and exhaustive physical alertness (Jackson \& Turkington, 2005). Other species display a variety of defensive reactions in response to predators, some understood as correlated states of anxiety (Rodgers et al., 1995). Rodents demonstrate anxiety, fear and curiosity when placed in a new environment, and an overall assessment of behavior could be determined through the observation of freezing, grooming (fear), rearing, head-dips (curiosity) and the number of fecal boluses (Onaivi et al., 1992; Costa-Campos et al., 2004). Ethereal fractions did not change the number of grooming.

Bauhinia genus is used empirically in Brazil for treating diabetes (Lorenzi \& Matos, 2002). Some chemical compounds, from the flavonoids, coumarin, triterpenoids/ steriods and tannins categories, have been identified. None of these fractions have demonstrated to possess sedative properties. Ethnomedical and pharmacological knowledge about this plant would allow us to presume that it has an anxyolitic activity on CNS, which could be oriented to decrease anxiety states in patients.

The ethanolic extract, aqueous fraction and ethyl acetate fractions of leaves from $B$. platypetala did not showed anxiolytic-like, amnesic or sedative effects.

However, in the present work, a clear anxiolyticlike activity only for ethereal fraction at dose $50 \mathrm{mg} / \mathrm{kg}$ (i.p.) prepared with ethanolic extract from B. platypetala has been demonstrated. This fraction was able to significantly increase the time spent and number of entries of mice in the aversive spaces of the plus-maze test. These results indicate anxiolytic activity comparable to the DZP, the standard anxiolytic drug. In the case of plus-maze test, this effect was not showed by ethanolic extract and others fractions from B. platypetala studied, which cannot be necessarily attributed to the compounds concentration in chemistry identification in the ethereal fraction from $B$. platypetala. The ethanolic extract and fractions from $B$. platypetala did not have antidepressant effects.

Moreover, ethanolic extract and fractions from $B$. platypetala did not demonstrate antidepressant effects in forced swimming test. So we did not perform experiments on animals with a combination of pretreatment with ethanolic extract and fractions obtained of the leaves from $B$. platypetala with antidepressant standard drugs (impramine, paroxetine and reserpine) in this test, since the initial results were not satisfactory and there was a plausible justification for assessing the potential antidepressant and there was no significant change in time immobility suggesting an antidepressant action for the species studied.

Nevertheless, it is possible to speculate that such discrepant findings could be related to the tenuous structural differences among ethereal fraction. Therefore, from the above results, it can be concluded that the ethanol extract derived from $B$. platypetala could be considered as potential alternative for possible applications in pharmaceutical industry for the prevention of anxiety. Therefore, further studies need to be performed in order to elucidate the antianxiety mechanisms of ethereal fraction and its potential clinical use in the treatment of anxiety.

\section{Acknowledgments}

We would like to thank the National Council of Technological and Scientific Development (CNPq/ Brazil) [grant number 503354/2009-0] and the Research Supporting Foundation of State of Piaui (FAPEPI/Brazil) for the financial support, Dra. Ângela Maria Studart da Fonseca Vaz by identification the plant, fellows of RMF and CMF from CNPq and Dr. Paulo Michel Pinheiro Ferreira (UFPI, Department of Biological Sciences, Picos, Piauí) for his help with English editing of the manuscript.

\section{References}

Almeida RN, Falcão A, Diniz RST, Quintans-Júnior LJ, Polari RM, Barbosa-Filho JM, Agra MF, Duarte JC, Ferreira CD, Antoniolli AR 1999. Metodologia para avaliação de plantas com atividade no sistema nervoso central e alguns dados experimentais. Rev Bras Farm 80: 72-76.

Andrews G, Sanderson K, Slade T, Issakidis C 2000. Why does the burden of disease persist? Relating the burden of anxiety and depression to effectiveness of treatment. Bull World Health Organ 78: 446-454.

Archer J 1973. Tests for emotionality in rats and mice: a review. Animal Behav 21: 205-235.

Barbosa WLR 2004. Manual para análise fitoquímica e cromatográfica de extratos vegetais. Rev Científica da UFPA 4: 12-18.

Costa-Campos L, Dassoler SC, Rigo AP, Iwu M, Elisabetsky E 2004. Anxiolytic properties of the antipsychotic alkaloid alstonine. Pharmacol Biochem Behav 77: 481-489.

Egan D, O'Kennedy R, Moran E, Cox D, Prosser E, Thornes RD 1990. The pharmacology, metabolism, analysis, and applications of coumarin and coumarin-related compounds. Drug Metab Rev 22: 503-529.

Ferreira PMP, Carvalho AFU, Farias DF, Cariolano NG, Melo VMM, Queiroz MGR, Martins AMC, Machado-Neto JG 2009. Larvicidal activity of the water extract of Moringa oleifera seeds against Aedes aegypti and its toxicity upon laboratory animals. An Acad Bras Cienc 81: 207-216.

Ferreira PMP, Carvalho AFFU, Sousa DF, Magalhães JF, Martins AR, Martins MAC, Queiroz MGR 2007. Water extract of Moringa oleifera seeds: a toxicological approach. REPM 1: 45-57. 
Fort DM, Jolad SD, Nelson ST 2001. Lithospermoside from Bauhinia fassoglensis (Fabaceae). Biochem Syst Ecol 4: 439-441.

Fuentes O, Arancibia-Avila P, Alarcón J 2004. Hypoglycemic activity of Bauhinia candicans in diabetic induced drabbits. Fitoterapia 75: 527-532.

Greenberg PE, Sisitsky T, Kessler RC, Finkelstein SN, Berndt ER, Davidson JR, Ballenger JC, Fyer AJ 1999. The economic burden of anxiety disorders in the 1990s. $J$ Clin Psychiatry 60: 427-435.

Griebel G, Perrault G, Simiand J, Cohen C, Granger P, Decobert M, Françon D, Avenet P, Depoortere H, Tan S, Oblin A, Schoemaker H, Evanno Y, Sevrin M, George P, Scatton B 2001. SL651498: an anxioselective compound with functional selectivity for 2- and 3-containing aminobutyric acid-A (GABAA) receptors. J Pharmacol Exp Ther 298: 753-768.

Hegazi AG, Abd El Hady FK 2002. Egyptian propolis: 3. Antioxidant, activities and chemical composition of propolis from reclaimed lands. Z Naturforsch 57: 395 402.

Hogg S 1996. A review of the validity and variability of the elevated plus-maze as an animal model of anxiety. Pharmacol Biochem Behav 54: 21-30.

Jackson MJ, Turkington D 2005. Depression and anxiety in epilepsy. J Neurol Neurosurg Psychiatry 76: 45-47.

Jordan AD, Kordik CP, Reitz AB, Sanfillipo PJ 1996. Novel anxiolytic agents-1994-to present. Expert Opin Ther Pat 6: 1047-1060.

Kaneko T, Tahara S, Takabayash F 2007. Inhibitory effect of natural coumarin compounds, esculetin and esculin, on oxidative DNA damage and formation of aberrant crypt foci and tumors induced by 1,2-dimethylhydrazine in rat colons. Biol Pharm Bull 30: 2052-2057.

Khalil NM, Pepato MT, Brunetti IL 2008. Free radical scavenging profile and myeloperoxidase inhibition of extracts from antidiabetic p lants: Bauhinia forficata and Cissus sicyoides. Biol Res 41: 165-171.

Kulkarni SK, Dhir A 2007. Effect of various classes of antidepressants in behavioral paradigms of despair. Prog Neuro-Psychopharmacol Biol Psych 31: 12481254.

Lister RG 1987. The use of a plus-maze to measure anxiety in the mouse. Psychopharmacology 92: 180-185.

Lorenzi H, Matos FJA 2002. Plantas medicinais do Brasil: nativas e exóticas. Instituto Plantarum, Nova Odessa, $512 \mathrm{p}$.

Masur J, Martz RMW, Carlini EA 1971. Effects of acute and chronic administration of Cannabis sativa and (-)- $\alpha 9-$ trans-tetrahydrocannabinol on the behavior of rats in an open field arena. Psychopharmacology 19: 338-397.

Matos FJA 2009. Introdução à fitoquímica experimental. Fortaleza: UFC.

Melo CTV, Monteiro AP, Leite CP, Araújo FL, Lima VT, Barbosa-Filho JM, Fonteles MMF, Vasconcelos SM,
Viana GSB, Sousa FC 2006. Anxiolytic-like effects of (O-methyl)- $N$-2,6-dihydroxybenzoyl-tyramine (Riparin III) from Aniba riparia (NeeS) Mez (Lauraceae) in mice. Biol Pharm Bull 29: 451-454.

Neichi T, Koshihara Y, Murota S 1983. Inhibitory effect of esculetin on 5-lipoxygenase and leukotriene biosynthesis. Biochim Biophys Acta 753: 130-132.

Nijveldt RJ, Van Nood E, Van Hoorn DE, Boelens PG, Van Norren K, Van Leeuwen PA 2001. Flavonoids: A review of probable mechanisms of action and potential applications. Am J Clin Nutr 74: 418-425.

Onaivi ES, Maguiri PA, Tsai, NF, Davies, MF, Locu GH 1992. Comparison of behavioral and central BDZ binding profile in three rat lines. Pharmacol Biochem Behav 43: 825-831.

Pan Y, Kong L, Xia X, Zhang W, Xia Z, Jiang F 2005. Antidepressant-like effect of icariin and its possible mechanism in mice. Pharmacol Biochem Behav 82: 686-694.

Pinheiro TS, Johansson LA, Pizzolatti MG, Biavatti MW 2006. Comparative assessment of kaempferitrin from medicinal extracts of Bauhinia forficata Link. $J$ Pharmac Biomed Anal 41: 431-436.

Platel A, Porsolt RD 1982. Habituation of exploratory activity in mice: a screening test for memory enhancing drugs. Psychopharmacology 78: 346-352.

Porsolt RD, Anton G, Blavet N, Jalfre M 1978. Behavioural despair in rats: a new model sensitive to antidepressant treatments. Eur J Pharmacol 47: 379-391.

Porsolt RD, Bertin A, Jalfre M 1977a. Behavioral despair in mice: a primary screening test for antidepressants. Arch Int Pharmacodyn Ther 229: 327-336.

Porsolt RD, Le Pichon M, Jalfre M 1977b. Depression: a new animal model sensitive to antidepressant treatments. Nature 266: 730-732.

Ratty AK, Das NP 1988. Effects of flavonoids on nonenzymatic lipid peroxidation: structure/activity relationship. Biochem Med Metab Biol 39: 69-79.

Reddy MVB, Reddy MK, Gunasekar D, Caux C, Bodo B 2003. A flavanone and a dihydrodibenzoxepin from Bauhinia variegatae. Phytochemistry 64: 879-882.

Rex A, Morgenstern E, Fink H 2002. Anxiolytic-like effects of kava-kava in the elevated plus maze test - a comparison with diazepam. Prog Neuro-Psychopharmacol Biol Psychiatry 26: 855-860.

Rickels K, Schweizer E 1997. The clinical presentation of generalized anxiety in primary-care settings: practical concepts of classification and management. J Clin Psychiatry 58: 4-9.

Rodgers RJ, Cole JC, Aboualfa K, Stephenson LH 1995. Ethopharmacological analysis of the effects of putative 'anxiogenic' agents in the mouse elevated plus-maze. Pharmacol Biochem Behav 52: 805-813.

Samarth RM, Panwa RM, Kumar M, Soni A, Kumar M, Kumar A 2008. Evaluation of antioxidant and radical-scavenging 
activities of certain radioprotective plant extracts. Food Chem 106: 868-873.

Tadano T, Nakagawasai O, Niijima F, Tan-No K, Kisara K 2000. The effects of traditional tonics on fatigue in mice differ from those of the antidepressant imipramine: a pharmacological and behavioral study. Am J Chin Med 28: 97-104.

United States Department of Agriculture 2007. Genus: Bauhinia L. Germplasm Resources Information Network.

Volpato DC, GT, Calderon IMP, Aguilar R, Rudge MVC 2004. Effect of Bauhinia forficata extract in diabetic pregnantrats: maternal repercussions. Phytomedicine 11: 196-201.

Volpato GT, Damasceno DC, Rudge MVC, Padovani CR, Calderon IP 2008. Effect of Bauhinia forficata aqueous extract on the maternal-fetal outcome and oxidative stress biomarkers of streptozotocin-induced diabetic rats. J Ethnopharmacol 116: 131-137.

Williamson EM, Okpako DT, Evans FJ 1982. Selection preparation and pharmacological evaluation of plant material. New York: John Wiley and Sons.

Wittchen HU, Hoyer J 2001. Generalized anxiety disorder: nature and course. J Clin Psychiatry 62: 15-21.

World Health Organization 2001. Director-General unveils new global strategies for mental health. Geneva: WHO.

Yadava RN, Tripathi P 2000. A novel flavone glycoside from the stem of Bauhinia purpurea. Fitoterapia 71: 88-90.

Yeh GY, Eisenberg DM, Kaptchuk TJ, Phillips RS 2003. Systematic review of herbs and dietary supplements for glycemic control in diabetes. Diab. Care 26: 12771294.

\section{*Correspondence}

Rivelilson Mendes de Freitas

Laboratório de Pesquisa em Neuroquímica Experimental, Universidade Federal do Piauí

Campus Universitário Ministro Petrônio Portella, Curso de Farmácia, Bairro Ininga, 64049-550 Teresina, Piauí, Brazil rivelilson@pq.cnpq.br Tel. +558632155870 